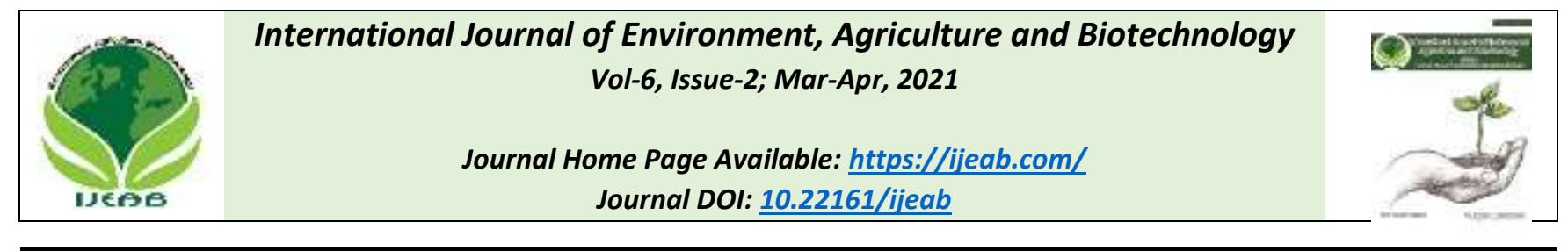

\title{
Effect of Poultry Manure Amendment on the Distribution and Mobility of Heavy Metals in Naturally Contaminated Dump Soil
}

\author{
Ezeudu Emeka Christian*, Elaigwu Daniel Enenche, Oli Christian Chukwuemeka, Obi \\ Amalachukwu Ifeyinwa, Vincent Ishmael Egbulefu Ajiwe, Patrice A. C. Okoye
}

Nnamdi Azikiwe University, Awka, Nigeria

*Corresponding Author

Received: 12 Dec 2020; Received in revised form: 15 Feb 2021; Accepted: 07 Mar 2021; Available online: 21 Mar 2021

(C2021 The Author(s). Published by Infogain Publication. This is an open access article under the CC BY license

(https://creativecommons.org/licenses/by/4.0/).

\begin{abstract}
In this study, the effect of poultry manure amendment on the availability of some heavy metals, $(\mathrm{Cu}, \mathrm{Cr}, \mathrm{Mn}$ and $\mathrm{Zn}$ ) was evaluated. The uptake of the metals by Ricinus communis (castor oil) with and without amendment was conducted in a green house. Soil sample was treated with 5\%, 10\% and 20\% of poultry manure in a pot experiment. There was an increase in physicochemical properties of the soil such as $\mathrm{pH}$, organic matter content and ECEC on treatment. Chemical speciation of the parent soil indicated that there was appreciable concentration of the metals in the extractable fraction. After three months of planting, the results showed that the extractability of the metals decreased significantly mostly with increase in percentage amendment. Residual fractionsgave the highest concentration of the metals and extractable having the least. $20 \%$ amendment has the best immobilization potential for $\mathrm{Cu}$ (7.07\%), $\mathrm{Cr}$ $(9.68 \%)$ and $\mathrm{Mn}$ (15.17\%). The results also showed that amendment decreased plant metal uptake, generally decreasing as percentage amendment increased. These findings will be useful in the assessment and remediation of heavy metal-contaminated soils.
\end{abstract}

Keywords—-poultry manure, soil amendment, heavy metal.

\section{INTRODUCTION}

Soil contamination by heavy metals is a major problem that has attracted much research interest the world over. In 2005 for instance, metals were the main contaminants reported to affect over 6000 sites studied in Denmark (Jensen et al., 2009) just as about 20000 sites were reported in England and wales (Environmental-Agency, 2004). Similarly, over 100000,80000 and 50000 pollution sites were reported in USA, European Union and Australia respectively (He et al. 2015). China may be the worst hit with about 14000000 ha sites reportedly contaminated by heavy metals (Sun et al. 2009). Not only do heavy metals occur naturally in parent rocks, but they emanate from other specific sourcesand anthropogenic activities such as mining, smelting, use of pesticides, fertilizers, sludge and emission from industries (Sawidiset al., 2014).
Following lessons from historic catastrophic heavy metal contamination, public awareness has grown with focus on the implications of contaminated soils environment on human and animal health (Mulligan et al., 2001; Bolan et al., 2003). Soil remediation has become expedient and has been so promoted. The remediation of metal contaminated sites is howevercost intensive and employs environmentally invasive practices. Different remediation strategies have been employed for metal contaminated soils, includingphysical and chemical treatments such as acid leaching and electro-reclamation, excavation and landfilling and thermal treatments(EPA 2006). These are however only effective enough to lower the risk (Jiang et al., 2009) and would be more ideal for relatively small contaminated sites (Basta and McGowen, 2004; Debela et al., 2012) since these techniques are expensive. 
Soil remediation using low-cost organic materials and wastes has been considered as a promising solution. Numerous amendments have been proposed and tested for soil stabilization, including agricultural and industrial byproducts. Lee et al. (2013) studied immobilization in a contaminated rice paddy soil using egg shell waste and reported that the toxicity of $\mathrm{Pb}$ and $\mathrm{Cd}$ was reduced by $93.2 \%$ and $67.9 \%$ respectively. Walkers et al. (2004) reported that amending a metal contaminated soil with cow manure increased the growth of Chenopodiumalbum and reduced shoot concentration of $\mathrm{Cu}, \mathrm{Mn}$ and $\mathrm{Zn}$. Sato et al. (2010) evaluated Cd phytoavailibilty in soils as effected by application of chemical fertilizer and three types of animal waste compost derived from cattle, swine and poultry wastes and reported that $\mathrm{Cd}$ concentration in spinach grown on soil amended with animal waste compost was $38 \%$ lower than in plants cultivated on chemical fertilizertreated soil. The effectiveness of stabilization strategy depends on the nature of the contaminants, physical and chemical characteristics of the amendment, and type of the soil.

Organic soil amendment harnesses thein situ stabilization of soils whereby an amendment is incorporated into a contaminated soil in order to immobilize heavy metals and reduce the uptake by plants without any side effect(Hartley and Lepp, 2008; Hosseini et al., 2013;). This method decreases the hazard potential of the contaminants into their least soluble, mobile or toxic form (Karbassinet al., 2014). Amendments may bind, absorb or co-precipitate metal contaminants, reducing metal mobility and availability. Organic amendments have been reported to decrease heavy metals bioavailability, shifting them from plant available forms that is extractable with water or neutral salts such as calcium chloride, to fractions associated with organic matter, carbonates or metal oxides (Walker et al., 2004). Consequently, functional groups present on the surface of organic amendments would provide binding sites for heavy metals.

\section{METHODOLOGY}

\section{Sample collection}

Soil samples were collected into plastic bags from several dump sites at Nnewi, Nigeria at $0-15 \mathrm{~cm}$ depth using a spade. The samples were air-dried, sieved with $2 \mathrm{~mm}$ sieve and then thoroughly mixed together before storing for further treatment. Poultry droppings were collected from a local farm in the study area,dried and ground for further assessment.

\section{Pot Experiment}

Pots with diameter of $14.0 \mathrm{~cm}$ and a height of $12.0 \mathrm{~cm}$ were filled with $2.0 \mathrm{~kg}$ of soil in a greenhouse. The poultry droppings were added to the soil at 5\%, $10 \%$ and $20 \%$ treatment in replicates. The treated soil samples were then thoroughly mixed, watered with deionized water and kept for two days in order to get equilibration of heavy metals between the amendments and the soils. Seeds of castor oil (Ricinus communis) were sown in each of the amended soil with thinning carried out on germination. The plants were uprooted after three months of germination, washed thoroughly with running water and deionized water respectively.

\section{Plant Analysis}

The harvested plants were dried for 72 hours at $60^{\circ} \mathrm{C}$ and later ground. The plant materials were digested with concentrated nitric acid (Lina et al., 2009) and heavy metals $(\mathrm{Pb}, \mathrm{Cr}, \mathrm{Mn}$, and $\mathrm{Cu}$ ) were determined using AAS (model-PG 990).

\section{Soil Analysis}

The physico-chemical properties $(\mathrm{pH}$, organic matter, exchangeable cation exchange capacity, particle size) of the parent soil samples and amended soil samples were determined by standard methods. Soil samples collected from each pot after plant harvesting and sequential extraction done for the soils. The various extracts wereanalysed for heavy metals using AAS (model-PG 990).

\section{Sequential extraction}

Sequential extraction was doneas described by Tessier et al. (1979) with modification as described by Sebasthiaret al., (2005), replacing percloric acid with aqua regia. All extracts were analyzed using AAS (model: PG-990).

\section{Exchangeable}

To $1 \mathrm{~g}$ of amended soil sample, $8 \mathrm{~mL}$ of $1 \mathrm{M} \mathrm{MgCl}_{2}$ was added with $\mathrm{pH}$ adjusted to 7.0 with agitation for $1 \mathrm{hr}$ before centrifuging for 15 mins. The supernatant was filtered into a polypropylene bottle for AAS analysis, while the residue was used for further extraction.

\section{Carbonate bound}

$1 \mathrm{M} \mathrm{NaOAc}(8 \mathrm{~mL})$ was added to the residue obtained from the exchangeable fraction above and then adjusted to $\mathrm{pH}$ 5.0 with concentrated acetic acid and agitated for $5 \mathrm{hrs}$. The mixture was then centrifuged at $15 \mathrm{rpm}$ for $15 \mathrm{mins}$. The supernatant was filtered into a polypropylene bottle for AAS analysis. 


\section{Fe-Mn Oxides}

$20 \mathrm{~mL}$ of $0.04 \mathrm{M} \mathrm{NH} \mathrm{N}_{2} \mathrm{OH}$.HClin $25 \%$ HOAc was added to the residue obtained from the carbonate bound fraction and placed in water bath for 6 hours at $96 \pm 3^{\circ} \mathrm{C}$. The mixture was then centrifuged at $1500 \mathrm{rpm}$ for $15 \mathrm{mins}$ beforethe supernatant was filtered into a polypropylene bottle for metal analysis.

\section{Bound to organic}

$3 \mathrm{~mL}$ of $0.02 \mathrm{M} \mathrm{HNO}_{3}$ and $5 \mathrm{~mL}$ of $30 \% \mathrm{H}_{2} \mathrm{O}_{2}$ adjusted to $\mathrm{pH} 2.0$ was added to the residue obtained from the step above and mixture was heated to $85 \pm 2^{\circ} \mathrm{C}$ for 2 hours. $3 \mathrm{~mL}$ of $30 \% \mathrm{H}_{2} \mathrm{O}_{2}$ was later added and mixture heated to $85 \pm 2^{\circ} \mathrm{C}$ for $3 \mathrm{hrs}$ before centrifuging at $1500 \mathrm{rpm}$ for 15 mins. The supernatant was filtered into a polypropylene bottle for metal analysis.

\section{Residual fraction}

Residue from the organic bound extraction was digested with $8 \mathrm{~mL}$ of aqua regia for 2 hrsbefore collecting for analysis.

\section{Determination of mobility factor}

The mobility factor which is the percentage fraction of heavy metals that are mobile or available for plant absorption was calculated thus:

$$
\mathrm{MF}=(\mathrm{F} 1+\mathrm{F} 2) /(\mathrm{F} 1+\mathrm{F} 2+\mathrm{F} 3+\mathrm{F} 4+\mathrm{F} 5) \times 100
$$

Where $\quad F 1=$ exchangeable fraction, $F 2=$ bound to carbonate, $\mathrm{F} 3=$ bound to $\mathrm{Fe}-\mathrm{Mn}$ Oxide, $\mathrm{F} 4=$ bound to organic, $\mathrm{F} 5=$ residual.

\section{DATA ANALYSIS}

Results are presented as mean value \pm standard deviation and analyzed by analysis of variance (ANOVA) using SPSS software package. Multivariate analysis was also used for the comparative immobilization effect of different manure amendments and forms of heavy metals in the dump soil. Statistically significant differences between means were determined by Least Significant Difference (LSD) at $95 \%$ confidence limit.

\section{RESULTS AND DISCUSSION}

\section{Physicochemical properties}

Table 1 shows the physicochemical properties of the amended and unamended soil samples. The pH, ECEC and organic matter of the dump soil increased with increase in manure amendment in the order, 20\%>10\%> 5\% resulting in change inconcentrations. The variation may be due to the different concentrations of manure especially since the change in values were statistically significant $(p<0.05)$. Increased application of poultry manure resulted to the reduction in the mobility factors of the metals. The increasein percentage organic matter detectedwhich is statistically significant $(\mathrm{p}<0.05)$ may be due to varying concentrations of poultry amendment. Mohammadi et al.,(2011) andHou et al., (2012) suggested that manure is an organic source of nutrients which increases the soil organic matter and enhances soil quality.

\begin{tabular}{lllll}
\hline & \multicolumn{3}{c}{ Manure Amendment } \\
\cline { 2 - 5 } & \multicolumn{1}{c}{ Control } & $\mathbf{5 \%}$ & $\mathbf{1 0 \%}$ & $\mathbf{2 0 \%}$ \\
\hline PH & $6.72 \pm 0.02$ & $6.73 \pm 0.01$ & $6.95 \pm 0.04$ & $7.10 \pm 0.05$ \\
\%Organic matter & $3.77 \pm 0.03$ & $4.21 \pm 0.00$ & $3.88 \pm 0.12$ & $4.15 \pm 0.01$ \\
ECEC (cmol/kg) & $14.58 \pm 0.07$ & $15.41 \pm 0.49$ & $19.11 \pm 2.50$ & $25.82 \pm 0.31$ \\
\% Sand & $93.8 \pm 0.00$ & $93.80 \pm 0.00$ & $93.80 \pm 0.00$ & $93.80 \pm 0.00$ \\
\% Silt & $2.8 \pm 0.00$ & $3.40 \pm 0.00$ & $3.40 \pm 0.00$ & $3.40 \pm 0.00$ \\
\% Clay & $3.4 \pm 0.07$ & $2.80 \pm 0.00$ & $2.80 \pm 0.00$ & $2.80 \pm 0.00$ \\
\hline
\end{tabular}

\section{Metal Distribution in Amended soils}

Tables 2 to 5 gives the distribution of various metals in the amended and unamended soils.

\section{Chromium}

The residual fraction of the extract contained the highest $\mathrm{Cr}$ for all amendments giving $54.00 \%, 56.40 \%$, and 61.70 $\%$ for $5 \%, 10 \%$ and $20 \%$ amendment respectively. The concentrations of $\mathrm{Cr}$ in the $5 \%$ sequential fraction followed the order; residual > bound to $\mathrm{Fe}-\mathrm{Mn}$ oxide> bound to organic > exchangeable > bound to carbonate; $10 \%$ wasresidual > bound to organic > bound to Fe-Mn oxide> exchangeable $>$ bound to carbonate and residual $>$ bound to organic >bound to Fe-Mn oxide> bound to carbonate> exchangeable. For $20 \%$ amendment. The mobile fractions of $\mathrm{Cr}$ available for plant absorption in dump soil amended 
with $5 \%, 10 \%$ and $20 \%$ of Poultry manure ranges from $9.68 \%-13.02 \%$ with the $20 \%$ amendment of poultry manure having the smallest amount.

\section{Copper}

The highest fraction obtained for $\mathrm{Cu}$ in dump soil amended with $5 \%, 10 \%$ and $20 \%$ of Poultry manure was obtained in the residual fraction while the lowest fraction was obtained in exchangeable fraction. For all the percentage amendments, the concentration of sequential fractions of $\mathrm{Cu}(\mathrm{mg} / \mathrm{kg})$ followed the order; residual > bound to organic > bound to Fe-Mn oxide > bound to carbonate > exchangeable. Residual fraction of $\mathrm{Cu}$ obtained in soil amended with $5 \%$ of Poultry manure is $56.50 \%$, lower than residual fraction obtained in the soil amended with $10 \%$ and $20 \%$ of Poultry manure that recorded $53.70 \%$ and $53.70 \%$ respectively. The exchangeable fraction of $\mathrm{Cu}$ obtained in the dump soil amended with $5 \%$ of Poultry manure is $3.70 \%$, higher than the exchangeable fraction obtained in the soil amended with $10 \%$ and $20 \%$ of Poultry manure that recorded $1.60 \%$ and $0.90 \%$ respectively.The mobile fractions available for plant absorption were $10 \%, 7.29 \%$, and $7.07 \%$ for soil amended with 5\%, $10 \%$ and $20 \%$ of Poultry manure respectively. It was observed that increase in \% amendment resulted to decrease in concentration of mobile fractions of $\mathrm{Cu}$ in dump soil.

\section{Manganese}

The residual fractions contained the highest fraction of $\mathrm{Mn}$ in all percentage amendments at $37.0 \%$ and $32.7 \%$ for $10 \%$ and $20 \%$ amendment respectively. Based on the $\mathrm{Mn}$ concentration $(\mathrm{mg} / \mathrm{kg})$, the sequential fraction as observed followed the order; residual > bound to Fe-Mn oxide > bound to organic > exchangeable > bound to carbonate fraction for $5 \%$ amendment, residual > bound to Fe-Mn oxide > bound to organic > exchangeable > bound to carbonate fraction for $10 \%$ amendment and residual > bound to organic > bound to Fe-Mn oxide > exchangeable $>$ bound to carbonate fraction for $20 \%$ amendment. The mobile fractions of $\mathrm{Mn}$ available for plant absorption in dump soil in order of decreasing fraction is $17.09 \%>$ $15.70 \%>15.17 \%$ for soil amended with $10 \%, 5 \%$ and $20 \%$ of poultry manure respectively. The mobile fractions of $\mathrm{Mn}$ was highest in the soil amended with $10 \%$ of Poultry manure but lowest in the soil amended with $20 \%$ of poultry manure.

\section{Zinc}

The fraction with highest concentration of $\mathrm{Zn}$ in dump soil amended with 5\%, $10 \%$ and $20 \%$ manure was obtained in the residual fraction while the lowest fractions were obtained in the exchangeable fractions. For all the percentage amendment, the concentration of sequential fractions of $\mathrm{Zn}(\mathrm{mg} / \mathrm{kg})$ followed the order; residual > bound to organic > bound to Fe-Mn oxide > bound to carbonate $>$ exchangeable. Residual fraction of $\mathrm{Zn}$ obtained in soil amended with $5 \%$ of Poultry manure is $52.80 \%$, higher than residual fraction obtained in the soil amended with $10 \%$ and $20 \%$ of Poultry manure that recorded $50.20 \%$ and $49.20 \%$ respectively. The mobile fractions of $\mathrm{Zn}$ available for plant absorption are $14.42 \%$, $15.43 \%$, and $15.04 \%$ for soil amended with $5 \%, 10 \%$ and $20 \%$ of poultry manure respectively. The order of mobile fractions of $\mathrm{Zn}$ available for plant absorption with respect to amendment with poultry manure is, $10 \%>20 \%>5 \%$ poultry manure amendment.

Table 2: Distribution of $\mathrm{Cr}$ in soil samples amended with 5\%, 10\% and 20\% poultry manure

\begin{tabular}{|c|c|c|c|c|c|c|c|c|}
\hline & \multicolumn{2}{|c|}{ Control } & \multicolumn{2}{|c|}{$5 \%$} & \multicolumn{2}{|c|}{$10 \%$} & \multicolumn{2}{|c|}{$20 \%$} \\
\hline & $\begin{array}{l}\text { Mean } \\
(\mathrm{mg} / \mathrm{kg})\end{array}$ & $\begin{array}{l}\% \\
\text { fraction }\end{array}$ & $\begin{array}{l}\text { Mean } \\
(\mathrm{mg} / \mathrm{kg})\end{array}$ & $\%$ fraction & $\begin{array}{l}\text { Mean } \\
(\mathrm{mg} / \mathrm{kg})\end{array}$ & $\begin{array}{l}\% \\
\text { fraction }\end{array}$ & $\begin{array}{l}\text { Mean } \\
(\mathrm{mg} / \mathrm{kg})\end{array}$ & $\%$ fraction \\
\hline F1 & $5.25 \pm 1.05$ & 11.41 & $2.58 \pm 0.36$ & 6.50 & $2.62 \pm 0.37$ & 6.60 & $1.79 \pm 0.29$ & 4.50 \\
\hline F2 & $9.63 \pm 1.29$ & 20.93 & $2.2 \pm 0.78$ & 5.50 & $2.55 \pm 0.17$ & 6.40 & $2.01 \pm 0.46$ & 5.10 \\
\hline F3 & $6.24 \pm 0.90$ & 13.56 & $7.49 \pm 2.46$ & 18.80 & $5.26 \pm 1.15$ & 13.20 & $3.66 \pm 0.86$ & 9.30 \\
\hline F4 & $11.67 \pm 2.07$ & 25.35 & $6.1 \pm 1.24$ & 15.30 & $6.87 \pm 1.27$ & 17.30 & $7.6 \pm 2.21$ & 19.40 \\
\hline F5 & $13.23 \pm 2.59$ & 28.75 & $21.58 \pm 3.6$ & 54.00 & $22.41 \pm 5.05$ & 56.40 & $24.21 \pm 4.71$ & 61.70 \\
\hline Sum & 46.03 & & 39.95 & & 39.71 & & 39.27 & \\
\hline Mf\% & 32.34 & & 11.96 & & 13.02 & & 9.68 & \\
\hline
\end{tabular}

Key: F1=Exchangeable, F2= Bound to Carbonate, F3= Bound to Fe-Mn oxide, F4= Bound to Organic, F5= Residual, Mf= Mobility factor 
Table 3: Distribution of $\mathrm{Cu}$ in soil samples amended with 5\%, $10 \%$ and $20 \%$ poultry manure

\begin{tabular}{|c|c|c|c|c|c|c|c|c|}
\hline & \multicolumn{2}{|c|}{ Control } & \multicolumn{2}{|c|}{$5 \%$} & \multicolumn{2}{|c|}{$10 \%$} & \multicolumn{2}{|c|}{$20 \%$} \\
\hline & Mean $(\mathrm{mg} / \mathrm{kg})$ & $\%$ fraction & $\begin{array}{l}\text { Mean } \\
(\mathrm{mg} / \mathrm{kg})\end{array}$ & $\%$ fraction & $\begin{array}{l}\text { Mean } \\
(\mathrm{mg} / \mathrm{kg})\end{array}$ & $\begin{array}{l}\% \\
\text { fraction }\end{array}$ & $\begin{array}{l}\text { Mean } \\
(\mathrm{mg} / \mathrm{kg})\end{array}$ & $\%$ fraction \\
\hline F1 & $8.28 \pm 1.07$ & 15.88 & $1.41 \pm 0.25$ & 3.70 & $0.66 \pm 0.06$ & 1.60 & $0.46 \pm 0.08$ & 0.90 \\
\hline F2 & $11.28 \pm 2.60$ & 21.64 & $2.4 \pm 0.41$ & 6.30 & $2.36 \pm 0.54$ & 5.70 & $2.96 \pm 0.39$ & 6.10 \\
\hline F3 & $7.30 \pm 0.34$ & 13.99 & $4.76 \pm 0.72$ & 12.50 & $7.16 \pm 1.34$ & 17.30 & $8.43 \pm 1.02$ & 17.40 \\
\hline F4 & $2.81 \pm 0.60$ & 5.40 & $7.99 \pm 2.91$ & 21.00 & $9.02 \pm 1.79$ & 21.80 & $10.55 \pm 2.72$ & 21.80 \\
\hline F5 & $22.47 \pm 3.41$ & 43.10 & $\begin{array}{l}21.55 \pm 3.9 \\
3\end{array}$ & 56.50 & $22.25 \pm 7.67$ & 53.70 & $26 \pm 3.97$ & 53.70 \\
\hline Sum & 52.15 & & 38.11 & & 41.45 & & 48.40 & \\
\hline Mf\% & 37.52 & & 10.00 & & 7.29 & & 7.07 & \\
\hline
\end{tabular}

Key: F1=Exchangeable, F2= Bound to Carbonate, F3= Bound to Fe-Mn oxide, F4= Bound to Organic, F5= Residual, Mf= Mobility factor

Table 4: Distribution of Mn in soil samples amended with 5\%, $10 \%$ and $20 \%$ poultry manure

\begin{tabular}{|c|c|c|c|c|c|c|c|c|}
\hline & \multicolumn{2}{|c|}{ Control } & \multicolumn{2}{|c|}{$5 \%$} & \multicolumn{2}{|c|}{$10 \%$} & \multicolumn{2}{|c|}{$20 \%$} \\
\hline & Mean $(\mathrm{mg} / \mathrm{kg})$ & $\begin{array}{l}\% \\
\text { fraction }\end{array}$ & $\begin{array}{l}\text { Mean } \\
(\mathrm{mg} / \mathrm{kg})\end{array}$ & $\%$ fraction & $\begin{array}{l}\text { Mean } \\
(\mathrm{mg} / \mathrm{kg})\end{array}$ & $\begin{array}{l}\% \\
\text { fraction }\end{array}$ & Mean $(\mathrm{mg} / \mathrm{kg})$ & $\begin{array}{l}\% \\
\text { fraction }\end{array}$ \\
\hline F1 & $21.64 \pm 3.54$ & 13.37 & $14.26 \pm 3.87$ & 10.40 & $14.8 \pm 3.21$ & 10.70 & $15.34 \pm 2.37$ & 8.6 \\
\hline F2 & $17.38 \pm 1.73$ & 10.74 & $7.33 \pm 2.69$ & 5.30 & $8.83 \pm 0.52$ & 6.40 & $11.66 \pm 1.11$ & 6.5 \\
\hline F3 & $54.27 \pm 6.31$ & 33.52 & $36.16 \pm 11.87$ & 26.30 & $36.33 \pm 6.02$ & 26.30 & $43.46 \pm 4.08$ & 24.4 \\
\hline F4 & $37.90 \pm 4.41$ & 23.41 & $30.46 \pm 11.93$ & 22.10 & $27.15 \pm 3.25$ & 19.60 & $49.38 \pm 5.46$ & 27.7 \\
\hline F5 & $30.70 \pm 4.19$ & 18.96 & $49.31 \pm 14.71$ & 35.90 & $51.15 \pm 11.66$ & 37.00 & $58.17 \pm 18.34$ & 32.7 \\
\hline Sum & 161.89 & & 137.52 & & 138.26 & & 178.01 & \\
\hline Mf\% & 24.10 & & 15.70 & & 17.09 & & 15.17 & \\
\hline
\end{tabular}

Key: F1=Exchangeable, F2= Bound to Carbonate, F3= Bound to Fe-Mn oxide, F4= Bound to Organic, F5= Residual, Mf= Mobility factor.

Table 5: Distribution of $\mathrm{Zn}$ in soil samples amended with 5\%, $10 \%$ and $20 \%$ poultry manure

\begin{tabular}{|c|c|c|c|c|c|c|c|c|}
\hline & \multicolumn{2}{|c|}{ Control } & \multicolumn{2}{|c|}{$5 \%$} & \multicolumn{2}{|c|}{$10 \%$} & \multicolumn{2}{|c|}{$20 \%$} \\
\hline & Mean $(\mathrm{mg} / \mathrm{kg})$ & $\begin{array}{l}\% \\
\text { fraction }\end{array}$ & $\begin{array}{l}\text { Mean } \\
(\mathrm{mg} / \mathrm{kg})\end{array}$ & $\%$ fraction & $\begin{array}{l}\text { Mean } \\
(\mathrm{mg} / \mathrm{g})\end{array}$ & $\begin{array}{l}\% \\
\text { fraction }\end{array}$ & $\begin{array}{l}\text { Mean } \\
(\mathrm{mg} / \mathrm{kg})\end{array}$ & $\%$ fraction \\
\hline F1 & $36.03 \pm 4.13$ & 19.04 & $4.44 \pm 1.11$ & 4.40 & $4.38 \pm 1.13$ & 3.90 & $3.21 \pm 0.35$ & 2.40 \\
\hline F2 & $42.81 \pm 5.19$ & 22.62 & $9.94 \pm 2.95$ & 10.00 & $13.15 \pm 3.25$ & 11.60 & $16.56 \pm 2.31$ & 12.60 \\
\hline F3 & $26.36 \pm 4.47$ & 13.93 & $15.76 \pm 3.75$ & 15.80 & $17.24 \pm 4.68$ & 15.20 & $23.02 \pm 31.91$ & 17.50 \\
\hline F4 & $18.48 \pm 3.46$ & 9.77 & $16.95 \pm 3.95$ & 17.00 & $21.81 \pm 6.91$ & 19.20 & $23.97 \pm 1$ & 18.20 \\
\hline F5 & $65.56 \pm 7.56$ & 34.64 & $\begin{array}{l}52.62 \pm 11.1 \\
5\end{array}$ & 52.80 & $\begin{array}{l}57.06 \pm 17.6 \\
2\end{array}$ & 50.20 & $64.7 \pm 21.91$ & 49.20 \\
\hline Sum & 189.24 & & 99.71 & & 113.64 & & 131.46 & \\
\hline Mf\% & 41.66 & & 14.42 & & 15.43 & & 15.04 & \\
\hline
\end{tabular}

Key: F1=Exchangeable, F2= Bound to Carbonate, F3= Bound to Fe-Mn oxide, F4= Bound to Organic, F5= Residual, Mf= Mobility factor 


\section{Mobility Factor and Plant Metal Uptake}

The effect of poultry manure amendment on mobility factor and plant metal uptake is shown in Figures 1 and 2.The total concentrations of the heavy metals available for absorption by Ricinus communis after amendment with different percentages of the manures used are calculated and presented as mobility factor. An increase inpoultry manure amendment decreased the mobility factor just as metal uptake by plant decreased. Plant metal uptake was decreased in the poultry manure amended soil compared with plant metal uptake in the unamended soil. Lowest mobility was recorded in the plant with lowest plant metal uptake. Alloway and Jackson (1991) corroborated this results in a similar study where it was reported that the metal uptake from soil to plant was slow because organic matter introduces new binding sites to the soil and therefore present fewer risk for plants, as compared to unamended soils. Similar effects for biochars and biosolids of poultry manure was studied by Uchimiyaet al. (2012) and Wuanaet al. (2012).

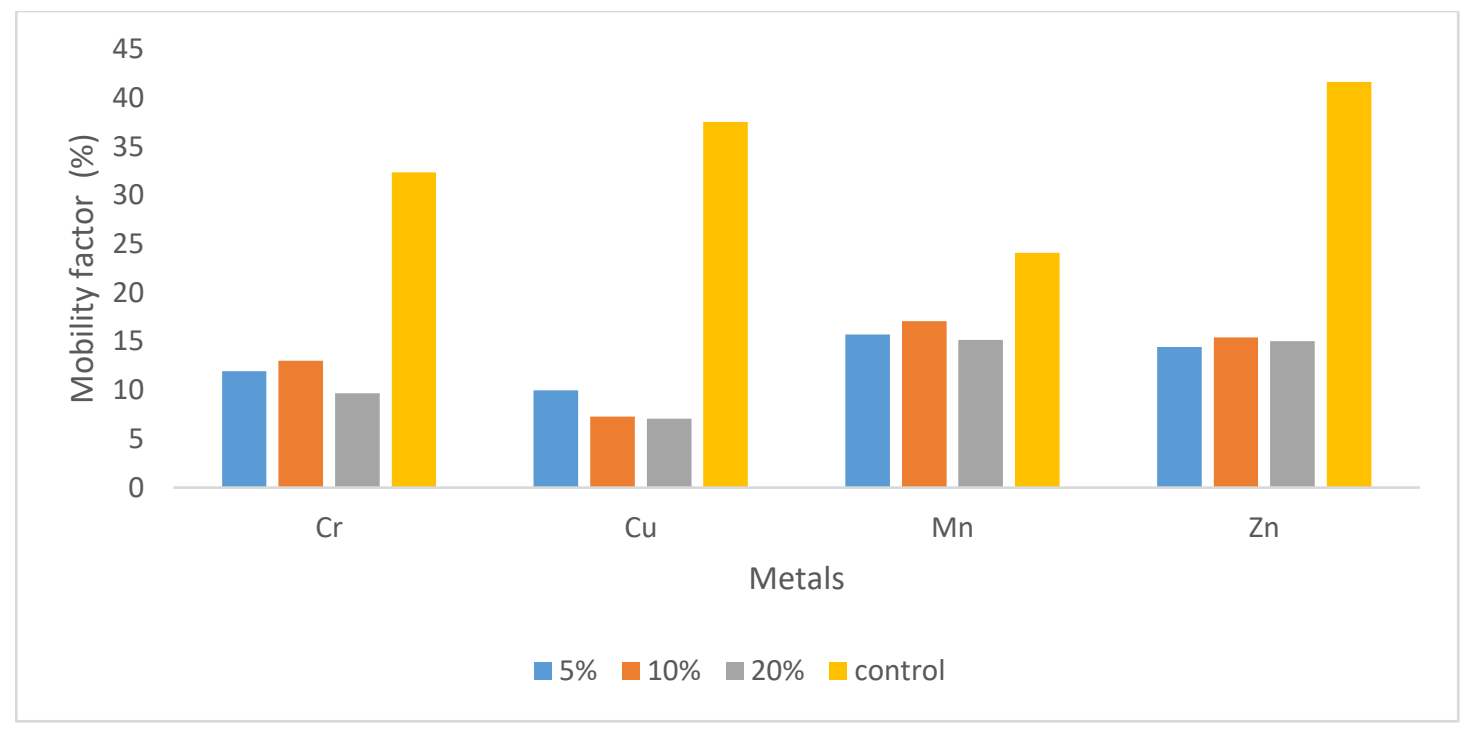

Fig.1: Effect of manure amendment on mobility factor (Mf)

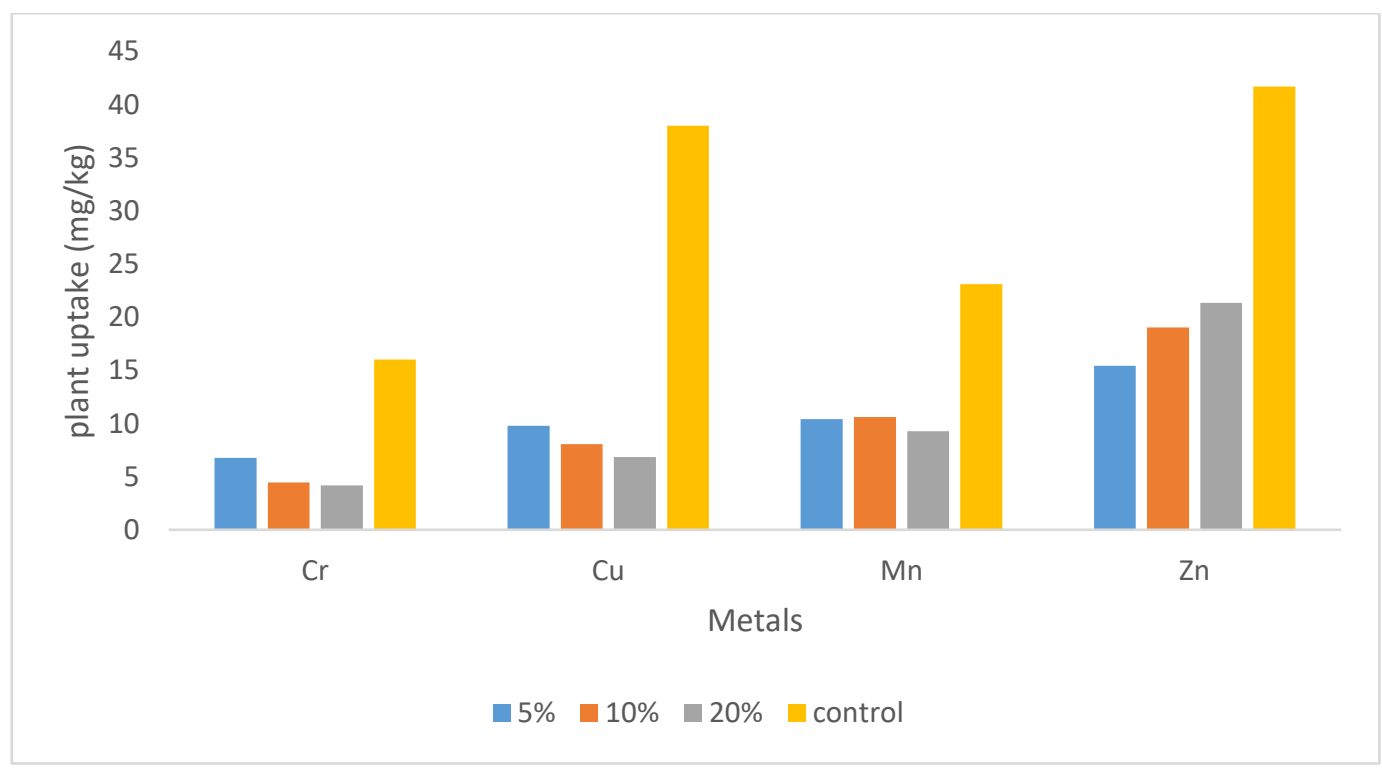

Fig.2: Effect of manure amendment on plant metal uptake

\section{DISCUSSION}

Application of poultry manure increased $\mathrm{pH}, \mathrm{ECEC}$ and organic matter resulting in change inconcentrations as well as reduction in the mobility factors of the metals. Generally, the concentrations of the heavy metals present in the dump soil changed in increasing order of residual > 
bound organic > bound to Fe-Mn oxide >bound to carbonate > exchangeable. Results from Azeez et al. (2019) however disagrees with the current findings reporting anorder of abundance of the fractions in dump soil amended with poultry manure was carbonate bound $>\mathrm{Fe}-\mathrm{Mn}$ oxides bound > exchangeable. Nonetheless, they reported that the application of poultry manure resulted in reduction in the available $\mathrm{Zn}$, exchangeable $\mathrm{Zn}$ and oxidebound $\mathrm{Zn}, \mathrm{Pb}$ and $\mathrm{Cd}$ in line with the finding of this research. According to Azeez and his colleagues, the reason for the high carbonate-bound heavy metals in the dumpsites reported in their work could be attributed to the fact that most of the heavy metals were in association with carbonate salts. Poultry manure amendments has been reported for $\mathrm{Cu}$ optimization in the contaminated soil (Thomas and Dauda, 2015); but according to Walker et al. (2003) the release of phosphate, carbonates and other salts after the application of composted poultry manure may transform into metal insoluble compounds and decreased metal solubility.

The immobilization effect of poultry manure on various heavy metals as seen in this research is in agreement with the reports of Irshad et al. (2014) and Wuanaet al. (2012). This may be due to the presence of trace metal (TM) sorbents capable of reducing TM solubility and enhancing immobility in the soil as reported by Haroon et al. (2019). Hanc et al. (2008) reported that poultry manure and compost decreased the available $\mathrm{Cd}$ and $\mathrm{Cu}$ content of contaminated soil. Lina, et al. (2009) also reported a decrease of soluble/exchangeable fraction of $\mathrm{Cd}$ and increase in organic-bound fraction when compared with the control. This also agreed with the current findings. Okieimen et al. (2011) while reporting stated that total uptake of $\mathrm{Cr}$ and $\mathrm{Cu}$ by maize plant decreased with increased loads of poultry amendment to the contaminated soil. These reductions were as associated with the capacity of the amendment to immobilize metals in soils. They stated that the organic matter and phosphorus content of organic amendment could account for the immobilization of metals.

Plant metal uptake shows that increase in percentage manure amendment decreased the mobility factor which also resulted in decrease in plant metal uptake this in agreement to the report of Angeloveet al. (2010) who reported that organic amendment reduced the concentration of $\mathrm{Pb}, \mathrm{Zn}, \mathrm{Cu}$ and $\mathrm{Cd}$ in potato tubers . Italso showed that the immobilization potential of the manure increased as their concentration in the soil was increased implying that poultry manure is a good immobilizing agent for remediation of heavy metal contaminated soil. The manure amendment significantly $(\mathrm{p}$ $<0.05)$ decreased the metalconcentrations in the extractable fraction (exchangeable and bound to carbonate) when compared with un-amended soil.

\section{CONCLUSION}

The concentrations of all the metals in each of the soil fractions significantly $(\mathrm{p}<0.05)$ varied for amendment with poultry manure. It was observed that $\%$ amendment with poultry manure significantly affected the forms of $\mathrm{Cd}, \mathrm{Cu}$, $\mathrm{Mn}$, and $\mathrm{Zn}(\mathrm{P}<0.05)$. Multiple comparison between 5\%, $10 \%$, and $20 \%$ of poultry manure revealed that $20 \%$ of poultry manure has more effect on the forms of $\mathrm{Mn}$, and Cd while $10 \%$ of poultry manure has more effect on geochemical forms of $\mathrm{Zn}$ and $\mathrm{Cu}$.The finding also shows that higher percentage amendment immobilizes metals more than lower percentage amendment except for $\mathrm{Cd}$ where immobilization effect decreases with percentage amendment.

\section{REFERENCES}

[1] Alloway, B.J. and Jackson, A.P. (1991). The behaviour of heavy metals in sewage sludge amended soils. The science of the Total Environment: 151-176.

[2] Angelove, V., Ivanov, R., Pevicharova, G. and Ivanov, K. (2010). Effects of organic amendments on heavy metals uptake by potato plants. $19^{\text {th }}$ world congress of soil science. Soil solution for a changing world. Brisbane, Australia.

[3] Azeez, J. O., Olowoboko, T. B., Ajenifuja, M. D., Ilebor, N. and Adekoya, E. (2019). Speciation of Some Heavy Metals as Influenced by Poultry Manure Application in Dumpsite Soils. Journal of Applied Sciences, 19(5): 497489.

[4] Basta, N.T. and McGowen, S.L. (2004). Evaluation of chemical immobilization treatments for reducing heavy metal transport in a smelter-contaminated soil. Environmental Pollution, 127: 73-82.

[5] Bolan, N.S., Adriano, D.C., Duraisamy, P., Mani, A. and Arulmozhiselvan, K. (2003). Immobilization and phytoavailability of cadmium in variable charge soils: Effect of phosphate addition. Plant. Soil, 250: 83-94.

[6] Debela, F., Thring, R.W. and Arocena, J.M. (2012). Immobilization of heavy metals by co-pyrolysis of contaminated soil with woody biomass, water, air and soil. Pollution, 223: 1161-1170.

[7] Environment Agency. (2004).The state of soils in England and Wales. Environment Agency, Bristol, UK.

[8] EPA. (2006). In-situ treatment technology for contaminated soil. EPA/F-06/013, U.S. Environmental Protection Agancy, Washington D.C. https://cluin.org/download/remed/542fo6013.pdf,

[9] Hanc, A., Tlustos, P., Szakovo, J., Harbart, J. and Gondek, K. (2008). Direct and subsequent effect of compost and poultry manure on the bioavailability of cadmium and copper and their uptake by oat biomass. Plant Soil Environ, 54(7): 271-278. 
[10] Haroon, B., Hassan, A., Abbasi, A. M., Ping, A., Yang, S., and Irshad, M. (2019). Effects of co-composted cow manure and poultry litter on the extractability and bioavailability of trace metals from the contaminated soil irrigated with wastewater. Journal of Water Reuse and Desalination, 1-13. https://doi.org/10.2166/wrd.2019.141.

[11] Hartley, W. and Lepp, N.W. (2008). Arsenic and heavy metal mobility in iron oxide-amended contaminated soils as evaluated by short and long term leaching tests. Environment pollution, 156: 1030-1040.

[12] He, Z., Shentu, J., Yang, X., Baligar, V.C., Zhang, T., Stoffela, P.J. (2015). Heavy metal contamination soils: sources, indicators and assessment. Journal of Environmental Indicators, 9:17-18.

[13] Hosseini, H., Shirani, H., Hamidpour, M., Karimi, R.R.,Shamshiri, M.H. and Dashti, H. (2013). Effects of natural and modified montmorillonite on plant availability of $\mathrm{Cd}$ (II) and $\mathrm{Pb}$ (II) in polluted soils. Environmental Engineering and Management Journal, 12: 2079-2086.

[14] Hou, X., Wang, X., Li, R., Jia, Z., Liang, L., Junpeng, W., Nie, J., Chen, X. and Wang, Z. (2012). Effects of different manure application rates on soil properties, nutrient use, and crop yield during dryland maize farming. Soil Research, 50: 507-514.

[15] Irshad, M., Malik, A. H., Shaukat, S., Mushtaq, S., and Ashraf, M. (2013). Characterization of Heavy Metals in Livestock Manures. Pol. J. Environ. Stud 22(4): 12571262.

[16] Jensen, J.K., Holm, P.E., Nejrup, J., Larsen, M.B. and Borggaard, O.K. (2009). The potential of willow for remediation of heavy metal polluted calcareous urban soils. Environmental Pollution, 157: 931-937.

[17] Jiang, C., Sun, H., Sun, T., Zhang, Q., Zhang, Y. (2009). Immobilization of cadmium in soils by uv-treated Bacilus subtilis 38 bioaugumentation and NOVOGRO amendment. Journal of Hazardous Materials, 167: 1170-1177.

[18] Karbassin, A., Nasrabadi, T., Rezai, M. andModabberi, S. (2014). Pollution in agricultural soil located close to Zarshuran gold mine, Iran. Environment Engineering and Management Journal. 13: 151-120.

[19] Lee, S.S., Lim, J.E., El-Azeem, S.A.M., Choi, B., Oh, S.E., Moon, D.H. and Ok, Y.S. (2013). Heavy metal immobilization in soil near abandoned mines using egg shell waste and rapeseed residue. Environmental Science and Pollution Research, 20: 1719-1726.

[20] Lina, L., Hansong, C., Peng, C., Wei, L. andQiaoyun, H. (2009). Immobilization and phytotoxicity of $\mathrm{Cd}$ in contaminated soil amended with chicken manure compost. Journal of Hazardous Materials, 163: 563-567.

[21] Mohammadi K, Heidari G, Khalesro S, and Sohrabi Y (2011) Soil management, microorganisms and organic matter interactions: A review. African Journal of Biotechnology 10: 19840-19849.

[22] Mulligan, C. N., Yong, R. N. and Gibbs, B. F. (2001). Remediation technologies for metal- contaminated soils and groundwater: An evaluation, Eng. Geol. 60: 193-207.

[23] Okieimen, F.E., Uwumarongie-Ilori, E.G. andIkhuoria, E.U. (2011). Effect of organic amendments on metal accumulation by maize (Zea mays L.) in contaminated soil. International Journal of AgriScience, 1(7): 366-372.

[24] Sato, A., Takeda, H., Oyanagi, W., Nishihara, E. and Murakami, M. (2010). Reduction of cadmium uptake in spinach (Spinacia oleracea L.) by soil amendment with animal waste compost. Journal of Hazardous Materials, 181: 298-304.

[25] Sawidis, T., Halley, J.M., Llupo, S., Bellos, D., Veros, D. andSymeondis, L. (2014). Nickel and iron concentrations in plants from mining area Pogradec, Albania. Environmental Engineering and Management Journal, 13: 861-872.

[26] Sebasthir, E., Ammaiyappa, S., Kyrian, J. and Kandasamy, P. (2005). Assessment of heavy metal species in decomposed municipal solid waste. Chemical speciation and bioavailability.17(3): 95-102.

[27] Sun, Y.B., Zhou, Q.X., Liu, W.T., An, J., Xu, and Z.Q. Wang, L. (2009). Joint effects of arsenic and cadmium on plant growth and metal bioaccumulation: A potential $\mathrm{Cd}$ hyperaccumulator and As-excluder Bidenspilosa. Journal of Hazardous materials, 165: 1023-1028.

[28] Tessier, A., Campbel, P.G.C and Bisson, M. (1979). Sequential procedure for the speciation of particulate trace metals. Anal.Chem 51(7): 844-851

[29] Thomas, E. Y. and Dauda, S. O. (2015). Comparative effects of compost and poultry manure on bioavailability of $\mathrm{Pb}$ and $\mathrm{Cu}$ and their uptake by maize (Zea mays L.). New York Sci. J. 8 (7): 23-34.

[30] Uchimiya, M., Cantrell, K.B., Hunt, P.G., Novak, J.M. and Chang, S.C. (2012). Retention of heavy metals in a typic kandiudult amended with different manure-based biochars. J. Environ. Qual. 41: 1138.

[31] Walker, D. J., Clemente, R., Roig, A. and Bernal, M. P. (2003). The effects of soil amendments on heavy metal bioavailability in two contaminated Mediterranean soils. Environ. Pollut. 122 (2): 303-312.

[32] Walker, D.J., Clemente, R. and Bernal, M.P. (2004). Contrasting effect of manure and compost on soil $\mathrm{pH}$, heavy metal availability and growth of Chenopodium album L. in soil contaminated by pyritic mine waste. Chemosphere, 57: 215-224.

[33] Wuana R.A., Okieimen F.E. and Ogoh B. (2012) Chemical fractionation and phytoavailability of heavy metals in a soil amended with metal salts or metal-spiked poultry manure. Commun. Soil Sci. Plan. 43: 2615-2632. 